\title{
Estudo comparativo do perfil facial de indivíduos Padrões I, II e III portadores de selamento labial passivo
}

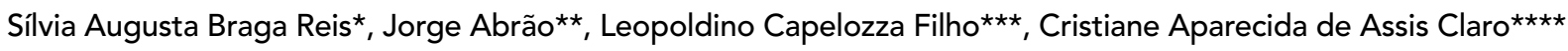

\section{Resumo}

Objetivo: avaliar as características numéricas do perfil facial. Metodologia: avaliou-se uma amostra de 50 indivíduos, brasileiros, adultos, leucodermas, portadores de selamento labial passivo, classificados pela avaliação morfológica do perfil em 41\% Padrão II e 9\% Padrão III. A análise facial numérica do perfil foi realizada em fotografias padronizadas. As medidas obtidas para as variáveis estudadas nos dois padrões foram comparadas entre si e com as do Padrão I por meio da Análise de variância (ANOVA) complementada pelo Teste de Tukey. Resultados e Conclusões: não foram observadas diferenças estatísticas entre os Grupos Padrão I, II e III nas medidas obtidas para os ângulos nasolabial e do sulco mentolabial e a proporção entre as alturas faciais média e inferior. O ângulo interlabial foi mais obtuso no Padrão III. Esse Padrão também apresentou menor convexidade facial e menor proporção do terço inferior da face. $\mathrm{O}$ ângulo do terço inferior da face, que avalia a protrusão mandibular, foi mais obtuso no Padrão II.

Palavras-chave: Diagnóstico ortodôntico. Análise facial. Fotometria.

\section{INTRODUÇÃO}

A análise morfológica da face é o principal recurso diagnóstico para determinação do Padrão Facial que, por sua vez, remete a protocolos de tratamento e prognósticos específicos em diferentes faixas etárias ${ }^{3}$.

A classificação do Padrão é realizada pela avaliação da face nas visões frontal e lateral. Os indivíduos podem ser classificados como Padrão I, II, III, Face longa ou Face curta. O Padrão I é identificado pela normalidade facial. A má oclusão quando presente é apenas dentária não associada a qualquer discrepância esquelética sagital ou vertical.
Os Padrões II e III são caracterizados pelo degrau sagital respectivamente positivo e negativo entre a maxila e a mandíbula. Nos Padrões face longa e face curta a discrepância é vertical. Nos pacientes com erros esqueléticos, as más oclusões são geralmente conseqüentes dessas discrepâncias.

$\mathrm{Na}$ avaliação do perfil, o Padrão I é caracterizado por um grau moderado de convexidade. A expressão da maxila na face é identificada pela presença da projeção zigomática e depressão infraorbitária, que podem ser verificadas também na visão frontal. A linha de implantação do nariz, levemente inclinada para anterior, denota adequada posição maxilar.

* Doutoranda em Ortodontia pela USP - São Paulo. Professora Assistente do Departamento de Ortodontia da Universidade Metodista de São Paulo.

** Professor Livre Docente da Faculdade de Odontologia da Universidade de São Paulo.

*** Professor Doutor da Faculdade de Odontologia da Universidade de São Paulo - Bauru. Membro do setor de Ortodontia do HRAC - USP - Bauru.

**** Doutoranda em Ortodontia pela USP - São Paulo. Professora Colaboradora Assistente da Disciplina de Ortodontia do Departamento de Odontologia da Universidade de Taubaté. 
O sulco naso-geniano com leve inclinação posterior completa a avaliação do equilíbrio maxilar. O ângulo nasolabial avalia a base nasal em relação ao lábio superior, cuja posição é fortemente determinada pela inclinação dos incisivos superiores. Portanto, esse ângulo pode estar adequado, aberto ou fechado nos pacientes Padrão I, como conseqüência da posição dos dentes anteriores superiores, independente do bom posicionamento maxilar, sempre observado nestes pacientes ${ }^{3}$.

O equilíbrio mandibular, tamanho, forma e posição, podem ser verificados na avaliação do perfil por meio da linha queixo-pescoço. Ela deve ser expressiva sem ser excessiva e tender ao paralelismo com o Plano de Camper. Esse paralelismo contribui para um ângulo adequado entre as linhas do queixo e do pescoço. Além disso, espera-se um ângulo mentolabial agradável esteticamente e construído com igual participação do lábio e do mento ${ }^{3}$.

Os pacientes portadores dos Padrões II e III apresentam discrepância sagital entre a maxila e a mandíbula identificada, principalmente, na avaliação lateral da face. Indivíduos classificados como Padrão I na visão frontal e II ou III no perfil apresentam melhor prognóstico que aqueles Padrões II ou III nas visões frontal e lateral, nos quais o desequilíbrio é grave o suficiente para ser identificado na avaliação de frente devido às suas conseqüências verticais.

O Padrão II apresenta convexidade facial aumentada em conseqüência do excesso maxilar, mais raro, ou pela deficiência mandibular². Normalmente, observa-se uma maxila com boa expressão na face, enquanto o terço inferior está deficiente e com a linha queixo-pescoço curta.

No Padrão III a convexidade facial apresenta-se reduzida, resultando em um perfil reto ou mais raramente côncavo devido à deficiência maxilar, ao prognatismo mandibular ou à associação de ambos. O terço médio da face tende a parecer deficiente mesmo que ele esteja normal, pois o excesso mandibular desloca para anterior o tecido mole da maxila, mascarando a leitura da projeção zigomática ${ }^{3}$. O terço inferior da face tende ao aumento, principalmente no prognatismo, e a linha queixo-pescoço apresenta-se normal nos deficientes maxilares ou em excesso nos prognatas.

Os pacientes classificados como Padrões face longa e face curta apresentam uma discrepância vertical visível nas avaliações de frente e perfil. O Padrão face longa é caracterizado pelo excesso na altura facial, resultando em ausência de selamento labial, convexidade facial aumentada, expressão maxilar deficiente e linha queixo-pescoço curta. O paciente Padrão face curta é identificado pela deficiência nas dimensões verticais, lábios comprimidos, maxila com expressão adequada e excesso da linha queixo-pescoço, devido à rotação anti-horária da mandíbula.

O estudo das medidas do perfil por meio da Análise facial numérica, considerando as limitações do método ${ }^{8,9}$, é indispensável para a análise comparativa das discrepâncias com a normalidade, planejamentos cirúrgicos e para o ensino aos neófitos na especialidade.

A análise facial numérica do perfil deve ser realizada em fotografias padronizadas ${ }^{10}$, por meio de medidas angulares e proporcionais, não influenciadas pelo tamanho da fotografia ou pela distância entre a máquina e a face do paciente, permitindo a comparação de valores obtidos em imagens com diferentes ampliações.

\section{PROPOSIÇÃO}

Os objetivos do presente estudo foram:

1) Definir as medidas das variáveis da Análise facial numérica do perfil para os Padrões II e III portadores de selamento labial passivo.

2) Comparar os resultados obtidos entre si e com os valores do Padrão I.

\section{MATERIAL E MÉTODOS}

A amostra do presente estudo foi obtida a partir de uma grupo composto por 100 brasileiros, adultos, leucodermas, selecionados por apresentarem selamento labial passivo, sendo 50 do gênero 

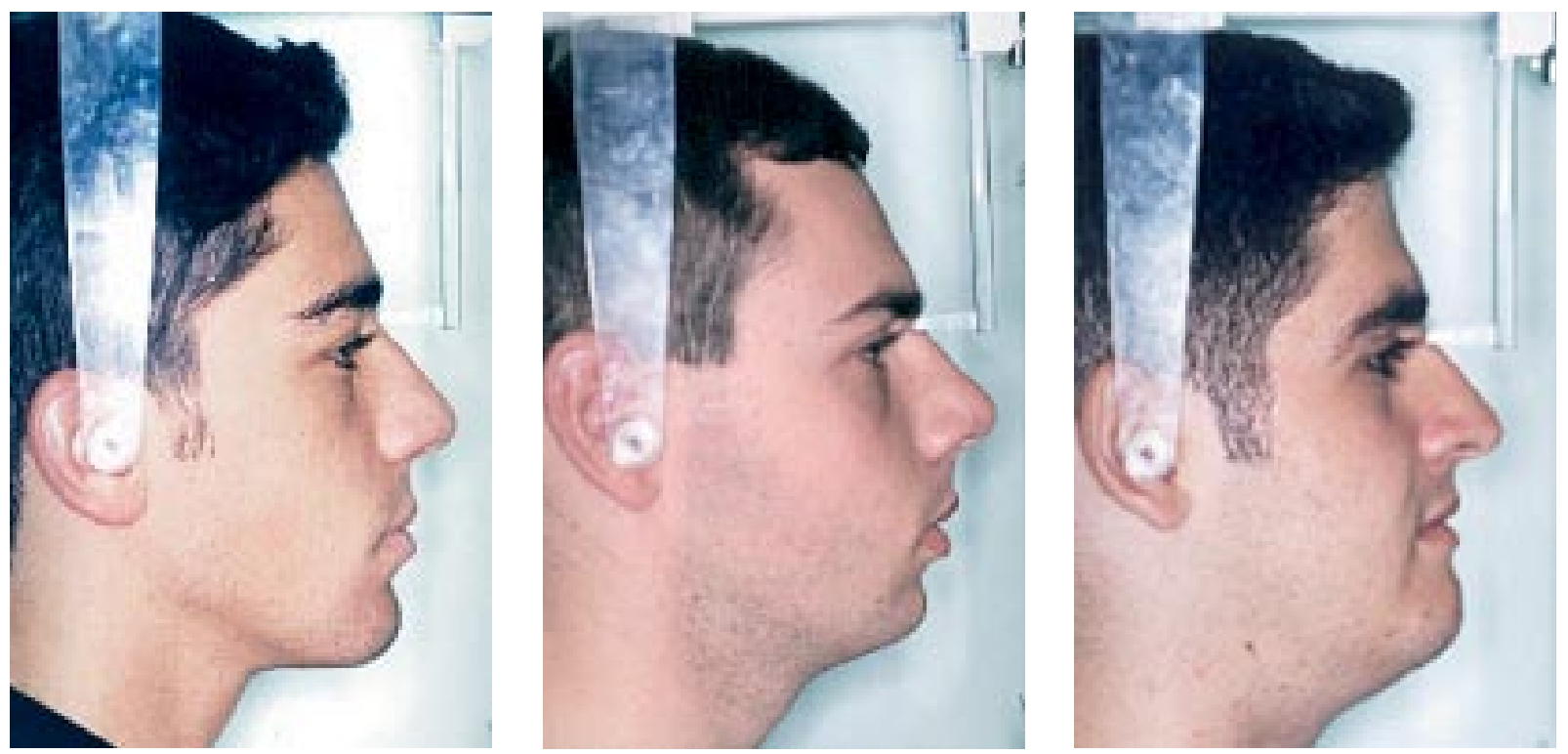

FIGURA 1 - Fotografias padronizadas do perfil de indivíduos portadores dos Padrões Faciais I, II e III.

masculino e 50 do feminino, com idade média de 23 anos e 7 meses, variando entre 18 e 36 anos $^{6,8}$. Nenhum dos pacientes foi submetido previamente a tratamento ortodôntico ou cirurgia plástica facial. As fotografias faciais padronizadas do perfil facial desses pacientes foram utilizadas nesta pesquisa ${ }^{6,8,10}$.

$\mathrm{Na}$ análise morfológica das fotografias do perfil, realizada por dois examinadores experientes, de acordo com as características dos Padrões descritas por Capelozza Filho ${ }^{3}$, observou-se 50\% de indivíduos Padrão I, 41\% Padrão II e 9\% Padrão III (Fig. 1). Aqueles classificados como Padrões II e III foram selecionados para o presente trabalho. Esse grupo de 50 indivíduos foi constituído por 18 do gênero feminino e 32 do masculino. $\mathrm{O}$ grupo $\mathrm{Pa}$ drão II foi composto por 15 indivíduos do gênero feminino e 26 do masculino, enquanto no Padrão III essa distribuição foi de 3 e 6 , respectivamente.

Todos os indivíduos que aceitaram participar da presente pesquisa assinaram um termo de consentimento que esclarecia os objetivos do trabalho e os exames aos quais seriam submetidos. No termo de consentimento, os participantes autorizavam ainda a divulgação de suas fotografias faciais para fins de ensino e pesquisa.

As médias de idade e os desvios padrões dos grupos Padrão II e Padrão III foram, respectivamente $23 \mathrm{a}$ e $7 \mathrm{~m} \pm 3 \mathrm{a}$ e $7 \mathrm{~m}$ e $26 \mathrm{a} \pm 4 \mathrm{a}$.

A Análise Facial Numérica do Perfil dos grupos Padrão II e Padrão III foi realizada utilizando as seguintes grandezas ${ }^{5}$, já descritas anteriormente ${ }^{9}$ :

1) Ângulo Nasolabial ${ }^{1}$ (Cm.Sn.Ls);

2) Ângulo do Sulco Mentolabial (Li.Lm.Pg');

3) Ângulo Interlabial ${ }^{7}$ (Sn.Ls.Li.Lm);

4) Ângulo de Convexidade Facial (G.Sn.Pg');

5) Ângulo de Convexidade Facial Total ${ }^{1}$ (G.Pr. Pg');

6) Ângulo do Terço Inferior da Face (Sn.Gn'.C);

7) Proporção entre a Altura Facial Anterior Média e a Altura Facial Anterior Inferior (AFAM/ AFAI);

8) Proporção do Terço Inferior da Face.

As fotografias foram traçadas e medidas por dois avaliadores. Para avaliação do erro do método foram utilizados os testes $t$ de Student para avaliação do erro sistemático e de Dahlberg para avaliação do erro casual (Tab. 1, 2).

No grupo Padrão II observou-se diferença estatística entre as medidas realizadas para os ângu- 
Tabela 1 - Avaliação do erro interobservador das variáveis da Análise Facial Numérica do Perfil do grupo Padrão II.

\begin{tabular}{|c|c|c|c|c|c|c|}
\hline \multirow{2}{*}{ variáveis } & \multicolumn{2}{|c|}{ avaliador $\mathbf{A}$} & \multicolumn{2}{|c|}{ avaliador B } & \multirow{2}{*}{ p } & \multirow{2}{*}{ Dahlberg } \\
\hline & média & d.p. & média & d.p. & & \\
\hline ângulo nasolabial & $106,96^{\circ}$ & $11,47^{\circ}$ & $106,66^{\circ}$ & $11,45^{\circ}$ & 0,36 & $1,49^{\circ}$ \\
\hline ângulo do sulco mentolabial & $129,43^{\circ}$ & $11,71^{\circ}$ & $128,73^{\circ}$ & $11,83^{\circ}$ & 0,107 & $1,95^{\circ}$ \\
\hline ângulo interlabial & $131,15^{\circ}$ & $12,28^{\circ}$ & $130,95^{\circ}$ & $11,73^{\circ}$ & 0,558 & $1,48^{\circ}$ \\
\hline ângulo convexidade facial & $15,91^{\circ}$ & $4,31^{\circ}$ & $15,25^{\circ}$ & $4,57^{\circ}$ & $0,008^{* *}$ & $1,15^{\circ}$ \\
\hline ângulo convexidade facial total & $135,29^{\circ}$ & $4,42^{\circ}$ & $135,84^{\circ}$ & $4,5^{\circ}$ & $0,018^{*}$ & $1,07^{\circ}$ \\
\hline ângulo do terço inferior da face & $112,69^{\circ}$ & $8,94^{\circ}$ & $111,83^{\circ}$ & $9,69^{\circ}$ & $0,006^{* *}$ & $1,47^{\circ}$ \\
\hline proporção AFAM/AFAI & 0,94 & 0,37 & 0,92 & 0,1 & $<0,001^{* * *}$ & 0,10 \\
\hline proporção do terço inferior da face & 0,47 & 0,06 & 0,49 & 0,09 & 0,119 & 0,05 \\
\hline
\end{tabular}

*** $p<0,001,{ }^{* *} p<0,01,{ }^{*} p<0,05$

Tabela 2 - Avaliação do erro interobservador das variáveis da Análise Facial Numérica do Perfil do grupo Padrão III.

\begin{tabular}{|c|c|c|c|c|c|c|}
\hline \multirow{2}{*}{ variáveis } & \multicolumn{2}{|c|}{ avaliador $\mathrm{A}$} & \multicolumn{2}{|c|}{ avaliador B } & \multirow{2}{*}{$\mathbf{p}$} & \multirow{2}{*}{ Dahlberg } \\
\hline & média & d.p. & média & d.p. & & \\
\hline ângulo nasolabial & $104,44^{\circ}$ & $12,83^{\circ}$ & $103,33^{\circ}$ & $12,16^{\circ}$ & 0,117 & $1,49^{\circ}$ \\
\hline ângulo do sulco mentolabial & $137,28^{\circ}$ & $11,55^{\circ}$ & $134,83^{\circ}$ & $12,62^{\circ}$ & 0,264 & $4,42^{\circ}$ \\
\hline ângulo interlabial & $146,83^{\circ}$ & $21,55^{\circ}$ & $143,33^{\circ}$ & $18,19^{\circ}$ & 0,106 & $4,57^{\circ}$ \\
\hline ângulo convexidade facial & $5,94^{\circ}$ & $3,98^{\circ}$ & $6,17^{\circ}$ & $4,29^{\circ}$ & 0,736 & $1,28^{\circ}$ \\
\hline ângulo convexidade facial total & $142,5^{\circ}$ & $4,72^{\circ}$ & $143^{\circ}$ & $4,58^{\circ}$ & 0,371 & $1,11^{\circ}$ \\
\hline ângulo do terço inferior da face & $107,94^{\circ}$ & $7,47^{\circ}$ & $106,89^{\circ}$ & $7,22^{\circ}$ & $0,014^{*}$ & $1,01^{\circ}$ \\
\hline proporção AFAM/AFAI & 0,88 & 0,08 & 0,86 & 0,07 & 0,101 & 0,03 \\
\hline proporção do terço inferior da face & 0,41 & 0,02 & 0,41 & 0,03 & 0,628 & 0,02 \\
\hline
\end{tabular}

${ }^{* * *} p<0,001,{ }^{* *} p<0,01,{ }^{*} p<0,05$

los de Convexidade Facial, de Convexidade Facial Total, do Terço Inferior da Face e na Proporção entre as Alturas Faciais Média e Inferior (Tab. 1). Observa-se, entretanto, que além das médias encontradas pelos dois examinadores para essas variáveis serem muito semelhantes, os erros casuais identificados pelo teste de Dahlberg justificam a utilização dessas medidas no presente trabalho. O ângulo do terço inferior da face repetiu o achado anterior no Padrão III. Os ângulos do sulco mentolabial e o ângulo interlabial desse Padrão, entretanto, apresentaram valores do teste de Da- lhberg acima de $4^{\circ}$, considerado o valor máximo aceitável de erro. Esse resultado, entretanto, pode ser justificado pelo alto desvio-padrão observado para essas variáveis nesse grupo.

Obtidas as medidas de tendência central para cada variável, foi realizada a Análise de variância (ANOVA) e complementada pelo Teste de Tukey para comparação dos resultados dos dois grupos entre si e com as medidas de referência, estudadas em brasileiros Padrão I ${ }^{9}$.

As medidas do perfil facial dos indivíduos Padrão I foram abordadas em outro artigo ${ }^{9}$. 


\section{RESULTADOS E DISCUSSÃO}

O método de seleção da amostra utilizada no presente trabalho teve por objetivo incluir todos os indivíduos caracterizados pela normalidade funcional, representada pelo selamento labial passivo. Excluiu, portanto, os portadores de discrepâncias verticais, Padrões face longa e face curta, nos quais o erro vertical compromete a postura labial resultando em lábios respectivamente abertos e comprimidos. Foram excluídos também aqueles com protrusões dentárias que impedem o selamento labial, independente do Padrão. Esse método, entretanto, permitiu a inclusão de pacientes portadores de discrepâncias sagitais, Padrões II ou III, que, devido a compensações satisfatórias ocorridas durante o crescimento ou à menor gravidade da discrepância, são capazes de manter o equilíbrio funcional. Vários desses indivíduos (85\%), apesar de discrepantes no perfil, são classificados como Padrão I na visão frontal, pois a magnitude do erro presente não é suficiente para ser percebida de frente. Esses indivíduos apresentam melhor prognóstico para correção compensatória, e remotamente necessitariam de intervenção cirúrgica.

O uso da classificação do Padrão, proposta por Capelozza $^{3}$, remete a protocolos de tratamento, contenção e prognósticos específicos nas diferentes faixas etárias, resultado de vários anos de avaliações clínicas e dos estudos realizados em todo mundo.

Há, entretanto, uma dificuldade aos iniciantes nessa filosofia em classificar adequadamente a face pela análise morfológica, pressuposto indispensável à utilização dos benefícios da mesma. Essa dificuldade é observada principalmente nos portadores de discrepâncias leves e moderadas, e que conseguem preservar a normalidade funcional. Grandes discrepâncias são facilmente identificadas. Esse fato explica o método de inclusão dessa amostra.

Nesses casos, análise facial numérica pode ser utilizada como recurso diagnóstico complementar no auxílio da determinação do Padrão. A comparação das medidas obtidas para cada Padrão pode revelar as variáveis mais determinantes dos Padrões
II e III e auxiliar na identificação dos mesmos.

Para facilitar o entendimento, as variáveis da análise facial numérica serão discutidas em grupos.

\section{Ângulos que avaliam a protrusão labial}

Os ângulos nasolabial e do sulco mentolabial avaliam a protrusão dos lábios superior e inferior em relação à base nasal e ao mento, respectivamente. As medidas obtidas para esses ângulos nos padrões II e III estão descritas nas tabelas 3 e 4.

A comparação dos valores obtidos para essas duas variáveis, nos três grupos estudados, não apresentou diferenças (Tab. 5). Logo, essas medidas não são adequadas para o auxílio na diferenciação entre os Padrões I, II e III em pacientes adultos com discrepâncias moderadas e normalidade funcional.

Dois fatores podem contribuir para esse achado. Primeiro, a grande influência da inclinação dos dentes na determinação desses ângulos. Pacientes Padrão II com os incisivos superiores verticalizados e Padrão III com incisivos superiores protruídos podem apresentar o mesmo ângulo nasolabial presente no Padrão I. O segundo fator é o método de seleção da amostra que, ao incluir apenas pacientes caracterizados pela normalidade no perfil facial, já define a posição adequada dos lábios, independente do Padrão.

A média e o desvio padrão obtidos para o ângulo nasolabial no grupo Padrão II foram $106,96^{\circ} \pm$ $11,47^{\circ}$, variando entre $74,5^{\circ}$ e $131,1^{\circ}$, enquanto no grupo Padrão III houve uma tendência de redução do ângulo nasolabial, cujas medidas de tendência central foram $104,44^{\circ} \pm 12,83^{\circ}$, com o mínimo de $83^{\circ}$ e o máximo de $120,5^{\circ}$.

A observação das medidas obtidas para o ângulo do sulco mentolabial revela uma tendência desse ângulo estar mais fechado no Padrão II $\left(129,43^{\circ} \pm 11,71^{\circ}\right.$, com mínimo de $110^{\circ}$ e máximo de $\left.151,5^{\circ}\right)$ e mais aberto no Padrão III $\left(137,28^{\circ} \pm\right.$ $11,55^{\circ}$, com mínimo de $114,5^{\circ}$ e máximo de $\left.152^{\circ}\right)$ quando comparados ao Padrão I $\left(132,37^{\circ} \pm\right.$ $9,82^{\circ}$, com mínimo de $110,5^{\circ}$ e máximo de $152^{\circ}$ ). Esse achado pode ser explicado pela compensação 
Tabela 3 - Valores médio, mínimo e máximo, desvio padrão das grandezas da Análise Facial Numérica do Perfil dos indivíduos Padrão II ( $\mathrm{n}=41)$.

\begin{tabular}{|c|c|c|c|c|}
\hline variáveis & média & mínimo & máximo & d.p. \\
\hline ângulo nasolabial & $106,96^{\circ}$ & $74,5^{\circ}$ & $131,5^{\circ}$ & $11,47^{\circ}$ \\
\hline ângulo do sulco mentolabial & $129,43^{\circ}$ & $110^{\circ}$ & $151,5^{\circ}$ & $11,71^{\circ}$ \\
\hline ângulo interlabial & $131,15^{\circ}$ & $103^{\circ}$ & $160,5^{\circ}$ & $12,28^{\circ}$ \\
\hline ângulo convexidade facial & $15,91^{\circ}$ & $3,5^{\circ}$ & $24^{\circ}$ & $4,31^{\circ}$ \\
\hline ângulo convexidade facial total & $135,29^{\circ}$ & $127^{\circ}$ & $143^{\circ}$ & $4,42^{\circ}$ \\
\hline ângulo do terço inferior da face & $112,69^{\circ}$ & $97,5^{\circ}$ & $140^{\circ}$ & $8,94^{\circ}$ \\
\hline proporção AFAM/AFAI & 0,94 & 0,75 & 1,19 & 0,37 \\
\hline proporção do terço inferior da face & 0,47 & 0,37 & 0,64 & 0,06 \\
\hline
\end{tabular}

Tabela 4 - Valores médio, mínimo e máximo, desvio padrão das grandezas da Análise Facial Numérica do Perfil dos indivíduos Padrão III $(n=9)$.

\begin{tabular}{cccc}
\hline variáveis & média & mínimo & máximo \\
\hline ângulo nasolabial & $104,44^{\circ}$ & $83^{\circ}$ & $120,5^{\circ}$ \\
ângulo do sulco mentolabial & $137,28^{\circ}$ & $114,5^{\circ}$ & $12,83^{\circ}$ \\
ângulo interlabial & $146,83^{\circ}$ & $119,5^{\circ}$ & $11,55^{\circ}$ \\
ângulo convexidade facial & $5,94^{\circ}$ & $-0,5^{\circ}$ & $188,5^{\circ}$ \\
ângulo convexidade facial total & $142,5^{\circ}$ & $139,5^{\circ}$ & $11,5^{\circ}$ \\
ângulo do terço inferior da face & $107,94^{\circ}$ & $96,5^{\circ}$ & $151,5^{\circ}$ \\
proporção AFAM/AFAl & 0,88 & 0,80 & $115^{\circ}$ \\
proporção do terço inferior da face & 0,41 & 0,37 & 1,01 \\
\hline
\end{tabular}

Tabela 5 - Comparação das grandezas da Análise Facial Numérica do Perfil dos indivíduos Padrões I, II e III por meio da Análise de Variância (ANOVA) e do Teste de Tukey.

\begin{tabular}{|c|c|c|c|c|c|c|c|c|}
\hline variáveis & $\begin{array}{c}\text { média } \\
\text { Padrão I }\end{array}$ & $\begin{array}{c}\text { média } \\
\text { Padrão II }\end{array}$ & $\begin{array}{c}\text { média } \\
\text { Padrão III }\end{array}$ & $\mathbf{F}$ & $\begin{array}{c}\text { p } \\
\text { ANOVA }\end{array}$ & $\begin{array}{c}P \text { I } \\
x \\
P I I\end{array}$ & $\begin{array}{c}\mathbf{P I} \\
\mathbf{x} \\
\mathbf{P I I I}\end{array}$ & $\begin{array}{c}P \text { II } \\
x \\
\text { PIII }\end{array}$ \\
\hline ângulo nasolabial & $108,13^{\circ}$ & $106,96^{\circ}$ & $104,44^{\circ}$ & 0,4854 & 0,6169 & ns & ns & ns \\
\hline ângulo do sulco mentolabial & $132,37^{\circ}$ & $129,43^{\circ}$ & $137,28^{\circ}$ & 2,208 & 0,1154 & ns & ns & ns \\
\hline ângulo interlabial & $135,35^{\circ}$ & $131,15^{\circ}$ & $146,83^{\circ}$ & 5,71 & 0,004 & ns & $* *$ & $* * *$ \\
\hline ângulo convexidade facial & $12,32^{\circ}$ & $15,91^{\circ}$ & $5,94^{\circ}$ & 24,27 & $<0,001$ & * & $* * *$ & $* * *$ \\
\hline ângulo convexidade facial total & $137,85^{\circ}$ & $135,29^{\circ}$ & $142,5^{\circ}$ & 11,54 & $<0,001$ & ns & $* *$ & $* * *$ \\
\hline ângulo do terço inferior da face & $103,41^{\circ}$ & $112,69^{\circ}$ & $107,94^{\circ}$ & 13,73 & $<0,001$ & $* *$ & ns & ns \\
\hline proporção AFAM/AFAI & 0,93 & 0,94 & 0,88 & 1,564 & 0,2145 & ns & ns & ns \\
\hline proporção do terço inferior da face & 0,45 & 0,47 & 0,41 & 5,83 & 0,004 & ns & * & $* * *$ \\
\hline
\end{tabular}

${ }^{* * *} p<0,001,{ }^{* *} p<0,01,{ }^{*} p<0,05, n s=$ não significativo. 
que o incisivo inferior realiza na direção contrária ao erro esquelético, ou seja, protrusão no Padrão II, compensando o degrau sagital positivo e verticalização no Padrão III, compensando o degrau negativo existente entre a maxila e a mandíbula. Essa compensação é mais eficiente quanto mais equilibrado funcionalmente for o paciente.

O ângulo interlabial, por sua vez, apresentouse mais obtuso no Padrão III, quando comparado aos outros dois grupos, provavelmente devido à deficiência maxilar não totalmente compensada pela inclinação vestibular dos incisivos superiores e à verticalização dos incisivos inferiores, geralmente presente nos indivíduos desse Padrão ${ }^{3}$. Apesar do Padrão II ter apresentado um ângulo em média mais agudo que o Padrão I, essa diferença indica apenas uma tendência, pois não foi estatisticamente significante.

Conclui-se, portanto, que os ângulos nasolabial e do sulco mentolabial não apresentam diferenças entre os Padrões I, II e III com discrepâncias moderadas, enquanto o ângulo interlabial auxilia na identificação do Padrão III.

\section{Ângulos de convexidade facial}

Um dos aspectos que mais caracteriza o Padrão Facial no perfil é a convexidade do mesmo. Como esperado, o ângulo de convexidade facial apresentou diferenças estatísticas entre os três grupos. O Padrão III revelou o perfil menos convexo (Tab. 5), com medidas de tendência central de $5,94^{\circ} \pm 3,98^{\circ}$, variando entre $-0,5^{\circ}$ e $11,5^{\circ}$. No extremo oposto, o Padrão II apresentou o perfil mais convexo $\left(15,91^{\circ} \pm 4,31^{\circ}\right)$. As medidas obtidas para o Padrão I $\left(12,32^{\circ} \pm 3,93^{\circ}\right)$ devem ser a referência de normalidade para a comparação com os grupos discrepantes.

Apesar das limitações inerentes a qualquer medida realizada em fotografias, identificada, por exemplo, quando se encontra em um indivíduo Padrão II um ângulo de convexidade de $3,5^{\circ}$ e em um Padrão III um ângulo de $11,5^{\circ}$, esse ângulo mostrou-se sensível às diferenças existentes entre pacientes Padrões I, II e III com erros esqueléticos moderados.

O ângulo de convexidade facial total, o qual sofre grande influência da projeção nasal, identificou diferenças estatísticas apenas no Padrão III, quando comparado aos outros dois. As medidas obtidas para o Padrão III indicaram um perfil significativamente menos convexo (Tab. 4). Apesar dos valores obtidos para o Padrão II indicarem um perfil mais convexo comparados aos do Padrão I, essa diferença não foi estatisticamente significante.

A observação dos resultados mostra que os indivíduos Padrão III dessa amostra apresentavam discrepâncias mais marcantes no perfil que os Padrão II, quando comparados ao Padrão I. Pois, para o ângulo de convexidade, as diferenças foram significantes no Padrão III a 0,1\%, enquanto no Padrão II a diferença foi identificada apenas ao nível de significância de 5\%. O ângulo de convexidade facial total apenas identificou diferenças nas medidas do Padrão III.

\section{Ângulo do terço inferior da face}

O ângulo do terço inferior da face se propõe a avaliar a projeção anterior do mento. Sabemos, entretanto, que a posição do ponto cervical, alterada pelo acúmulo de gordura submandibular altera sobremaneira a medida desse ângulo ${ }^{9}$.

Comparando os três grupos, verificamos uma diferença significante entre as medidas obtidas para os Padrões I e II (Tab. 5). Esse último apresentou valores mais obtusos $\left(112,69^{\circ} \pm 8,94^{\circ}\right)$, o que indica menor projeção anterior do mento.

Contrariando o esperado, os valores obtidos para o Padrão III sugerem um ângulo mais obtuso $\left(107,94^{\circ} \pm 7,47^{\circ}\right)$ que no Padrão I $\left(103,41^{\circ} \pm\right.$ $8,12^{\circ}$ ). A diferença encontrada não foi, entretanto, estatisticamente significante e não pode ser considerada reproduzível.

O ângulo do terço inferior da face mostrou-se sensível no auxílio da identificação de indivíduos Padrão II, que apresentam esse ângulo mais obtuso devido à menor projeção do mento. 


\section{Proporções faciais}

$\mathrm{Na}$ avaliação dos perfis faciais espera-se que o terço inferior da face esteja reduzido em relação ao terço médio nos indivíduos Padrão $\mathrm{II}^{4}$, e aumentado nos Padrão III ${ }^{3}$.

O estudo da proporção entre as alturas faciais média e inferior confirmou essa tendência, sem, entretanto, apresentar diferença identificável nos testes estatísticos (Tab. 5, Gráf. 2).

Para o grupo Padrão II, os valores obtidos de média e desvio padrão foram $0,94 \pm 0,09$, enquanto no Padrão III verificou-se $0,88 \pm 0,08$. Essas medidas mostram uma tendência do terço inferior ser menor no primeiro grupo e maior no segundo quando comparados ao Padrão I $(0,93 \pm 0,10)$. Mas, a ausência de significância estatística não habilita essa medida a auxiliar na identificação dos Padrões II e III com discrepâncias moderadas.

Para a proporção do terço inferior da face fazse a mesma observação anterior. Espera-se uma altura de lábio inferior e mento, somadas, maior no Padrão III e menor no Padrão II. A medida novamente confirmou essa tendência, com valores maiores no Padrão II $(0,47 \pm 0,06)$ e menores no Padrão III $(0,41 \pm 0,02)$. Essa diferença só foi significativa, entretanto, para o Padrão III, quando comparado aos outros dois. Esse achado confirma a observação anterior de que os Padrões III dessa amostra são mais discrepantes que os Padrões II.

Deve-se ressaltar que a maior parte dessa amostra de indivíduos Padrões II e III (73\% e 55,5\%, respectivamente) foram classificados como Padrão I na avaliação frontal. Isso revela que a discrepân-

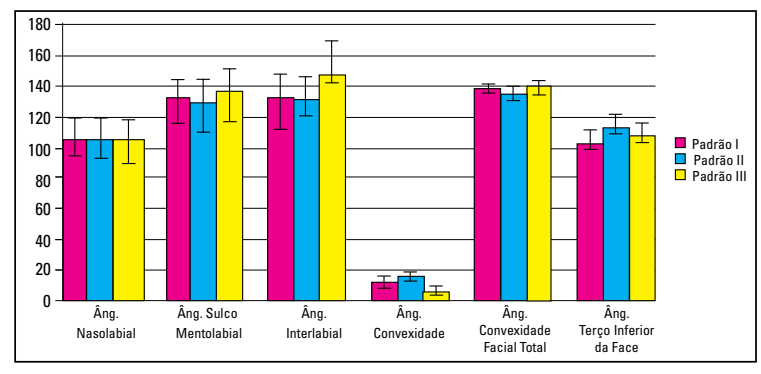

GRÁFICO 1 - Média e desvio padrão nos Padrões I, II e III para as variáveis angulares. cia não foi grave o suficiente para ser percebida na visão frontal. Se uma das principais alterações verificadas no frontal é a redução do terço inferior no Padrão II e o aumento do mesmo no Padrão III, pelo menos para os indivíduos Padrão I de frente não deveríamos esperar diferenças nessas medidas em relação ao Padrão I. Apenas naqueles classificados como Padrões II ou III nas visões frontal e lateral essas variáveis estariam alteradas.

Essas medidas serão, portanto, tanto mais significativas na identificação do Padrão, quanto mais discrepante for o paciente. Em erros esqueléticos moderados, apenas a proporção do terço inferior da face pode ser utilizada no auxílio da identificação do Padrão III.

\section{CONSIDERAÇÕES FINAIS}

Os tratamentos ortodônticos podem ser genericamente divididos em interceptivos ou corretivos. O tratamento corretivo, quando realizado em pacientes com discrepâncias esqueléticas, pode ser, por sua vez, compensatório primário, compensatório limitado ou associado à cirurgia ortognática. A utilização de protocolos definidos, que favorecem a comunicação com o paciente e diminuem as tentativas e erros na prática clínica, exige a identificação adequada do Padrão facial do paciente. A grande dificuldade de determinação do Padrão reside nos casos limítrofes, nos quais os erros esqueléticos são suaves ou moderados. A Análise Facial Numérica pode ser um recurso adicional no auxílio da determinação do Padrão nesses pacientes.

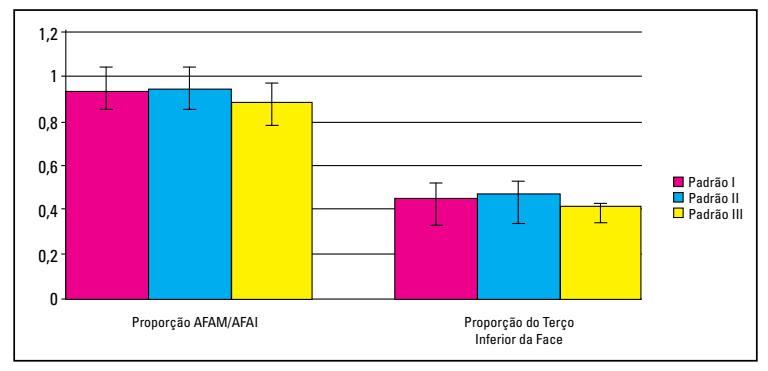

GRÁFICO 2 - Média e desvio padrão nos Padrões I, II e III para as variáveis proporcionais. 
De acordo com as conclusões desse trabalho, o Padrão III apresenta lábios menos protrusos, identificado pelo ângulo interlabial mais obtuso, convexidade facial reduzida, verificada pelos ângulos de convexidade facial e de convexidade facial total e excesso na altura de lábio inferior e mento somados em relação à altura do lábio superior, revelada pela menor proporção do terço inferior da face.

O Padrão II apresentou diferença significativa em relação ao Padrão I na convexidade facial, com ângulo de convexidade facial mais obtuso e no ângulo do terço inferior da face, mais aberto nesses pacientes, sugerindo menor projeção anterior do mento. Não foram observadas diferenças na inclinação labial ou nas proporções faciais.

A avaliação visual dos resultados obtidos nos gráficos 1 e 2 revela o descrito acima. Observe que os ângulos que medem a convexidade facial são os mais sensíveis à alteração do padrão facial.

Deve-se considerar que a amostra do presente estudo é composta por indivíduos de ambos os gêneros, que provavelmente apresentam diferenças na projeção do mento e do nariz. O estudo que avaliou a amostra total observou dimorfismo nos ângulos nasolabial e do terço inferior da face, além da proporção AFAM/AFAI ${ }^{8}$. Trabalhos subseqüentes devem ser realizados avaliando o dimorfismo dessas variáveis nos diferentes Padrões Faciais.

Observa-se, entretanto, que algumas das variáveis estudadas são diferentes nos Padrões I, II e III, mesmo em pacientes com selamento labial passivo. As diferenças numéricas observadas sugerem características morfológicas distintas para os três Padrões, as quais devem ser utilizadas como referência para a identificação do Padrão facial em casos limítrofes.

\section{CONCLUSÕES}

1) As médias e os desvios padrões das variáveis da Análise Facial Numérica do Perfil nos Padrões II e III, foram respectivamente $106,96^{\circ} \pm 11,47^{\circ} \mathrm{e}$ $104,44^{\circ} \pm 12,83^{\circ}$ para o ângulo nasolabial, $129,43^{\circ}$ $\pm 11,71^{\circ}$ e $137,28^{\circ} \pm 11,55^{\circ}$ para o ângulo do sulco mentolabial, $131,15^{\circ} \pm 12,28^{\circ}$ e $146,83^{\circ} \pm$ $21,55^{\circ}$ para o ângulo interlabial, $15,91^{\circ} \pm 4,31^{\circ}$ e $5,94^{\circ} \pm 3,98^{\circ}$ para o ângulo de convexidade facial, $135,29^{\circ} \pm 4,42^{\circ}$ e $142,5^{\circ} \pm 4,72^{\circ}$ para o ângulo de convexidade facial total, $103,41^{\circ} \pm 8,12^{\circ}$ e $112,69^{\circ} \pm 8,94^{\circ}$ para o ângulo do terço inferior da face. Esses mesmos valores foram 0,94 $\pm 0,09 \mathrm{e}$ $0,88 \pm 0,08$ para a proporção entre AFAM/AFAI e $0,47 \pm 0,06$ e $0,41 \pm 0,02$ para a proporção do terço inferior da face.

2) Não foram observadas diferenças estatísticas entre os grupos Padrão I, II e III nas medidas obtidas para os ângulos nasolabial e do sulco mentolabial e a proporção entre as alturas faciais média e inferior. $\mathrm{O}$ ângulo interlabial foi mais obtuso no Padrão III. Esse Padrão também apresentou menor convexidade facial e menor proporção do terço inferior da face. $\mathrm{O}$ ângulo do terço inferior da face, que avalia a protrusão mandibular, foi mais obtuso no Padrão II. 


\title{
Comparative analyses of facial profile among Patterns I, II and III faces with passive lip sealment
}

\begin{abstract}
Aim: the present study appraised the numerical characteristics of the facial profile. Methods: it was evaluated a sample of 50 individuals, 32 men and 18 women, between 18 and 36 years old, Brazilian, Caucasian, nonorthodontically treated, carrying an adequate muscular facial balance, showed by a passive lip sealment. Facial morphologic analysis of the profile detected $41 \%$ with Pattern II and $9 \%$ with Pattern III relationship between maxilla and mandible. Numeric facial analysis of the profile was performed in all photographs. One-way ANOVA test and Tukey's Pairwise comparison test were done to compare the results obtained with those of Pattern I patients, used as control group. Results and Conclusion: there were no statistical differences among Patterns I, II and III for nasolabial angle, mentolabial fold angle and the proportion between medium and lower facial heights. Interlabial angle was more obtuse in Pattern III group. This Pattern showed lower facial convexity and proportion of the lower third of the face. The angle of the lower third of the face, which measures mandibular protrusion was more obtuse in Pattern II group.
\end{abstract}

Key words: Orthodontic diagnosis. Facial analysis. Photometry.

\section{REFERÊNCIAS}

1. BISHARA, S. E.; HESSION, T. J.; PETERSON, L. C. Longitudinal soft-tissue profile changes: a study of three analyses. Am J Orthod Dentofacial Orthop, St. Louis, v. 88 , no. 3, p. 209-223, Sept. 1985.

2. BRANDÃO, A. M. B. et al. Avaliação comparativa entre as características da má oclusão Classe II div. 1 obtidas pela cefalometria e análise facial subjetiva. R Dental Press Ortodon Ortop Facial, Maringá, v. 6, n. 2, p.33-40, mar./abr. 2001.

3. CAPELOZZA FILHO, L. Diagnóstico em Ortodontia. Maringá: Dental Press, 2004.

4. CAPELOZZA FILHO, L. et al. A altura facial anterior inferior na Classe II divisão primeira por deficiência mandibular. R Dental Press Ortodon Ortop Facial, Maringá, v. 9, n. 6, p. 39-47, nov./dez. 2004.

5. LEGAN, H. L.; BURSTONE, C. J. Soft tissue cephalometric analysis for orthognathic surgery. J Oral Surg, v. 38, n. 10, p. 744-751, Oct. 1980.
6. MARTINS, L. F. Análise fotométrica em norma frontal de adultos, brasileiros, leucodermas, não tratados ortodonticamente, classificados pela estética facial. 2001. 159 f. Dissertação (Mestrado em Ortodontia)- Faculdade de Odontologia, Universidade Metodista de São Paulo, São Paulo, 2001.

7. MORRIS, W. An orthodontic view of dentofacial esthetics. Compend Contin Educ Dent, Lawrenceville, v .15, no. 3, p. 378-390, 1994.

8. REIS, S. A. B. Análise facial numérica e subjetiva do perfil e análise da relação oclusal sagital em brasileiros, adultos, leucodermas, não tratados ortodonticamente. 2001. $271 \mathrm{f}$. Dissertação (Mestrado em Ortodontia)-Faculdade de Odontologia, Universidade Metodista de São Paulo, São Paulo, 2001.

9. REIS, S. A. B.; ABRÃO, J.; CAPELOZZA FILHO, L.; CLARO, C. A. A. Análise Facial Numérica do Perfil de Brasileiros Padrão I. R Dental Press Ortodon Ortop Facial. No prelo.

10. SCANAVINI, M. A. et al. Novo dispositivo para obtenção de fotografias frontais e laterais padronizadas. J Bras Ortodon Ortop Facial, Curitiba, v. 8, n. 45, p. 245-250, maio/jun. 2003.

11. SCHEIDEMAN, G. B.; BELL, W. H.; LEGAN, H. L.; FINN, R. A.; REISCH, J. S. Cephalometric analysis of dentofacial normals. Am J Orthod, St. Louis, v. 78, no. 4, p. 404-420, Oct. 1980.
Endereço de correspondência

Sílvia Augusta Braga Reis

Rua Timbiras 1560 sala 308 - Bairro Lourdes

CEP: 30140-061 - Belo Horizonte/MG

silviabreis@hotmail.com 